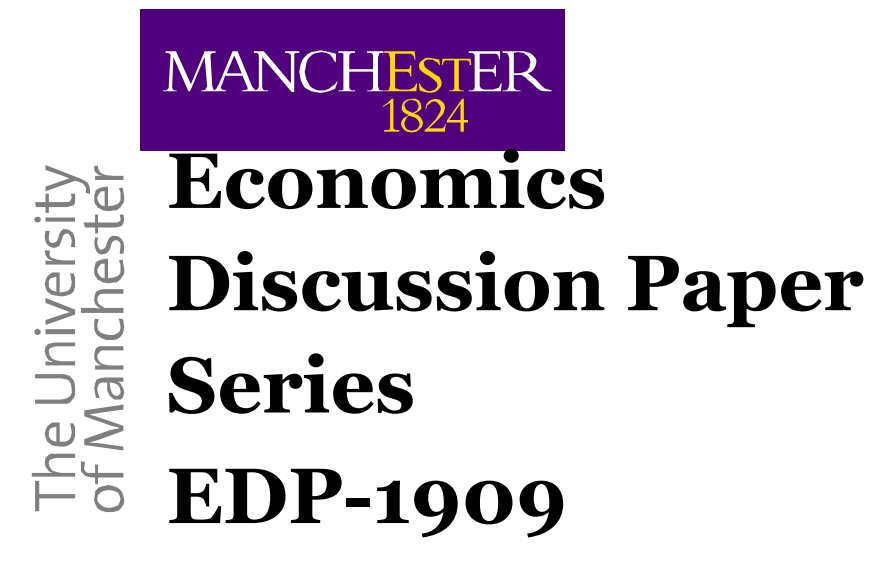

\title{
Much ado about nothing? \\ Online platform price parity \\ clauses and the EU Booking.com \\ case
}

\author{
Andrea Mantovani \\ Claudio Piga \\ Carlo Reggiani
}

May 2019

Economics

School of Social Sciences

The University of Manchester

Manchester M13 9PL 


\title{
Much ado about nothing? Online platform price parity clauses and the EU Booking.com case*
}

\author{
Andrea Mantovani
}

\author{
Claudio Piga
}

Carlo Reggiani

May 2019

\begin{abstract}
Online platforms often impose Price Parity Clauses to prevent sellers from charging lower prices on alternative sales channels. We provide quasi-experimental evidence on the full removal of Price Parity Clauses in France in 2015 and in Italy in 2017 for hotels listed on Booking.com. Our analysis reveals a relatively limited effect in the short run followed by a significant reduction in room prices in the medium run. Moreover, we find that hotels affiliated with chains decreased their prices more than independent hotels, both in the short and medium run. Overall, the policy interventions led to substantive savings for consumers.
\end{abstract}

JEL: D40, K21, L11, L42, L81.

Keywords: price parity clauses, online travel agents, hotel pricing, antitrust evaluation.

\footnotetext{
${ }^{*}$ Mantovani: University of Bologna, Department of Economics, 40126 Bologna, Italy (email: a.mantovani@unibo.it); Piga: Keele Business School, University of Keele, Staffordshire, ST5 5BG, United Kingdom (email: c.piga@keele.ac.uk); Reggiani: University of Manchester, Department of Economics, Manchester M13 9PL, United Kingdom (e-mail: carlo.reggiani@manchester.ac.uk). We are grateful to Martyn Andrews, James Banks, Annette Broocks, Joan Calzada, Vincenzo Denicolò, Renato Gomes, Rachel Griffith, Vicente Lagos, Ulrich Laitenberger, Ambre Nicolle, Luigi Pascali, Andrew Rhodes, John Rust, Marc Rysman, Yevgeniya Shevtsova, Tommaso Valletti, Antonio Vázquez, Thibaud Vergé, Chris Wallace, Mazhar Waseem, Julian Wright, Lorenzo Zirulia and seminar participants at the 10th Digital Economics Conference (ParisTech), 11th Digital Economics Conference (Toulouse School of Economics), XXXIII Jornadas de Economia Industrial (Barcelona), EARIE 2018 (Athens), IIOC 2018 (Indianapolis), IMAEF 2018 (Corfu), MaCCI 2018 (ZEW, Mannheim), TILEC 15th Anniversary Conference (Tilburg), Brunel Unversity, Competition and Market Authority, National University of Singapore, Ofcom, University of Loughborough, and Université Paris Nanterre for helpful comments and discussion. We also thank Lucy Scioscia for editorial assistance. The usual disclaimer applies.
} 


\section{Introduction}

Online platforms are under strict scrutiny in many countries for their dominant position and the use of controversial practices, notably the imposition of Price Parity Clauses. These clauses, which are widespread in many industries such as entertainment, insurance, digital goods, and payment systems, prevent a seller from offering the same product on other platforms or alternative sales channels for a lower price.

Price Parity Clauses raise consequential concerns as they can reduce price competition, incite high agency fees, and set off potential market foreclosure effects (Baker and Scott Morton, 2018; Fletcher and Hviid, 2017). Nonetheless, they are still generally legal in many countries, although in some, antitrust interventions have begun to prohibit them on an ad hoc basis that targets specific industries or platforms. So far, no compelling evidence exists on how the removal of these contractual restrictions have affected the pricing behavior of sellers operating on a platform.

Our analysis considers the lodging sector and exploits a series of laws that banned the use of Price Parity Clauses on online travel agencies (OTAs) in Europe between 2015 and 2017. We gather a large and detailed dataset on room level prices from hotels listed on Booking.com, the leading OTA in the EU. This allows us to provide quasi-experimental evidence on the short- and medium-run price effects of two specific institutional changes. In particular, we focus on the removal of Price Parity Clauses in France in 2015 and in Italy in 2017 and perform a difference-in-differences (D-in-D) analysis based on comparing prices posted on Booking.com by hotels in the neighboring Mediterranean islands of Corsica (France) and Sardinia (Italy), before and after the policy interventions.

The short-run analysis indicates no significant response of hotel prices on Booking.com. Chain hotels, however, displayed a more prompt reaction, lowering their prices between 5.6 and 8.6 percent. On the contrary, in the medium run all hotels decreased their prices by about 4 percent, with a further reduction on chain hotels of 12.3 percent. The latter effects indicate that, in the season after the law was introduced, tourists staying in the Corsican hotels of our sample may have saved between 7.4 and 8.6 million euros, half of which in chain hotels. 
Overall, we highlight a sluggish but significant price response to the elimination of Price Parity Clauses, although it played out in an heterogeneous way. Indeed, affiliation to a chain can spur the reaction through different mechanisms, such as faster dissemination of information, deployment of better managerial capabilities, and higher bargaining power when contracting commission fees with OTAs (Kosová and Lafontaine, 2012; Hollenbeck, 2017). The first two mechanisms seem to be particularly relevant in the short run, the third one in the medium run.

Price Parity Clauses, a particular type of "Most Favored Nation" vertical restraints, are usually divided into two types (Wang and Wright, 2018). In the context of the lodging sector, a "wide" Price Parity Clause requires the price charged by hotels on OTAs cannot be reduced when selling via alternative channels, including direct selling (e.g., the hotel website). A "narrow" Price Parity Clause is less rigid, as it allows hotels to reduce the price when selling through rival OTAs; in any case, they cannot charge a lower price when selling directly.

Both types of clauses have raised serious anti-competitive concerns. In response, antitrust authorities and policy makers have suggested that only their full elimination may enhance competition in a highly concentrated sector. ${ }^{1}$ For instance, according to the Bundeskartellamt (the German antitrust authority), narrow Price Parity Clauses do not provide sufficient incentives for hotels to price differentiate across sales channels. In fact, they may not want to offer a room on their own website at a higher price than on one of the OTAs they use. Hence, narrow Price Parity Clauses may de facto have the same anti-competitive effect as wide ones.

For this reason, we study in-depth the price effects of the legislative interventions banning every type of Price Parity Clauses in France (Macron Law, August 2015) and Italy (Liberalization Law, August 2017). We do so by focusing on a large sample of hotels listed on Booking.com in Corsica and Sardinia. These regions are geographically very close, and they represent comparable alternatives for potential visitors. ${ }^{2}$ Prices and detailed room

\footnotetext{
${ }^{1}$ Booking.com dominates the European OTA market with a 65.6 percent market share, as of 2017. Including Expedia and HRS, the aggregate market share is about $86 \%$. Source: HOTREC, available at: https://www.hotrec.eu/ european-hotel-distribution-study-2018/.

${ }^{2}$ These islands attract similar types of tourists not only for the beauty of their beaches,
} 
level characteristics are available before and after the legislative changes. In our main D-in-D analysis of the Macron Law, hotels in Corsica constitute the "treated group", whereas hotels in Sardinia are the "control group". The groups are simply "swapped" when studying the effect of Italy's Liberalization Law.

Gathering empirical evidence on the effects of eliminating Price Parity Clauses is particularly important as there is no current international consensus on the need to intervene. For example, antitrust authorities in the EU have brought cases against Amazon, prompting the company to drop these clauses in 2017. In the US, Amazon was compelled to do the same in 2019, but only as a result of political pressure, as no formal investigation was opened. More evidently, unlike the European experience, a recent complaint against OTAs in the US was dismissed without even addressing the question of whether or not Price Parity Clauses harm competition. ${ }^{3}$

Prominent academics and experts in the field are taking a firm stand on this issue. Fletcher and Hviid (2017) and Baker and Scott Morton (2018), for example, reiterated that prices are bound to increase due to platform Most Favored Nation clauses. The latter also stress that antitrust enforcement against Price Parity Clauses should be a priority in the US. Jean Tirole, in a recent interview, criticized these clauses, arguing that "if the platform is guaranteed the lowest price, there is no incentive for you to look anywhere else; you have become a "unique" customer, and so the platform can set large fees to the merchant to get access to you". ${ }^{4}$

The growing attention to the economic effects of Price Parity Clauses has attracted a large body of recent theoretical research (Boik and Corts, 2016; Johnson, 2017; Johansen and Vergé, 2017; Edelman and Wright, 2015; Wang and Wright, 2018; Wals and Schinkel, 2018; Ronayne and Taylor, 2019, inter alios), which provides the underpinning of our empirical analysis. A common trait of this literature is that prices are expected to decrease, both in direct channels and on platforms, following the removal

but also for their ancient culture, art, architecture, and for their cuisine, which is rooted in the traditional and distinct flavours and foods of the Mediterranean. The Mediterranean diet, for example, is part of the "Intangible heritage" protected by UNESCO.

${ }^{3}$ Online Travel Co. Hotel Booking Antitrust Litig., 997 F. Supp. 2d 526 (N.D. Tex. 2014)

${ }^{4}$ Econ Focus, Fourth Quarter 2017, available at: https://www.richmondfed.org/ publications/research/econ_focus/2017/q4/interview. 
of the clauses. ${ }^{5}$ The elimination of these restrictive contractual agreements should in fact enhance competition between sales channels, leading to lower commission fees passed through to prices. This is a medium-run effect, as it implies an adjustment or re-bargaining of platforms' fees. In the short run, only a minor effect on final prices is plausible.

Recent empirical research has tried to overcome the dearth of data in order to shed more light on this complex issue. Hunold et al. (2018) use metasearch data about hotels in different countries collected from Kayak during the period January 2016 to January 2017. They study hotels in Germany, where the Bundeskartellamt prohibited Booking.com from using all types of Price Parity Clauses in December 2015. They found the elimination of these contractual restrictions incentivized hotels to expand room availability on OTAs and increased the number of sales channels. Moreover, hotels charged the lowest price on the direct channel more often in Germany than in countries that did not abolish such clauses. Cazaubiel et al. (2018) consider a dataset of proprietary booking level data for a hotel chain in Oslo. Exploiting the chain's decision to delist from Expedia, they estimate the entity of the substitution between OTAs and the direct channel. Their findings hint to a strong loyalty of consumers to the chosen platform and a much higher substitutability between hotels.

Our article both differs and complements the empirical analysis carried out in the aforementioned studies. We are the first to directly investigate the price effects of removing Price Parity Clauses from Europe's most used OTA platform, Booking.com. Our data are scraped from its website: this allows an extremely precise matching of hotel rooms by type, characteristics, and quality. We track prices throughout an extensive booking period, enabling us to evaluate the behavior of prices before and after the policy changes. Moreover, our broad sample includes both a large number of independent establishments and chain hotels. This feature proves important for our results as chain hotels usually benefit from organizational experience (Baum and Ingram, 1998) and reputational advantages (Hollenbeck, 2017), thereby affecting their responsiveness to institutional changes.

This article also contributes to recent empirical evidence on the impact

\footnotetext{
${ }^{5}$ A notable exception is provided in the analysis by Johansen and Vergé (2017) when competitive pressure on the supplier side is relatively high.
} 
of regulation on platform pricing. Chen and Liu (2011) investigate the effects of Most-Favored Customer clauses on price competition among major electronics retail platforms. ${ }^{6}$ Unlike other markets, ${ }^{7}$ prices diminished after adopting these clauses. Ater and Rigbi (2018) evaluate the impact of a price transparency regulation imposed on Israeli supermarkets. Using a D-in-D approach, they document a price drop resulting from mandatory online disclosure. De los Santos and Wildenbeest (2017) also employ a D-in-D strategy to empirically investigate how different supplier-platform vertical relationships may affect retail prices. They exploit the US antitrust intervention in the e-book sector, that shifted back the pricing power from the e-book publishers to the distributing platforms. They show that this decision led to sharp price decreases.

Finally, to a lesser extent, our article relates to the recent stream of literature documenting the characterizing features of online prices on the basis of scraped data (Cavallo, 2017; Ellison, Snyder and Zhang, 2018; Gorodnichenko and Talavera, 2017, and Gorodnichenko, Sheremirov and Talavera, 2018, inter alios). Whereas online prices are usually more flexible than offline ones, the patterns are qualitatively comparable. Online prices, in fact, do not change for relatively long periods, exhibit substantial dispersion, and slowly adjust to changes in demand conditions. Our results confirm the presence of price stasis in hotel rooms pricing, and a rather sluggish short-run response to the policy interventions.

The rest of the article is structured as follows. Section 2 illustrates the main cases involving Booking.com in the EU, with a particular focus on the full removal of Price Parity Clauses in France and Italy. Section 3 presents the data. Section 4 presents some descriptives and explains our empirical strategy. Section 5 provides evidence on the short-run price effects, whereas Section 6 shifts the attention to the medium run. Section 7 concludes and draws the policy implications of our analysis.

\footnotetext{
${ }^{6}$ These clauses guarantee refunds to buyers in case future discounts by the same retailer become available on the product they purchased.

${ }^{7}$ Scott Morton (1997) and Crocker and Lyon (1994) focused respectively on pharmaceutical drugs and natural gas, markets in which prices increased over time after a Most-Favored Customer rule was added.
} 


\section{The EU Booking.com case}

In the period 2015-17, several important events occurred in the EU regarding the use of Price Parity Clauses. Table 1 briefly summarizes the main decisions, with a particular focus on those related to Booking.com.

Table 1: Main decisions on Price Parity Clauses (PPCs) in the EU, 2015-17

\begin{tabular}{|l|l|}
\hline \hline Apr 2015 & $\begin{array}{l}\text { Decisions by the French, Italian and Swedish competition authorities: } \\
\text { Booking.com commits to switch from wide to narrow PPCs } \\
\text { Jul 2015 }\end{array}$ \\
Booking.com's commitment comes into effect in the EU \\
Aug 2015 & Macron Law promulgated in France: all PPCs prohibited \\
Oct 2015 & Italian Parliament proposes a law to eliminate all PPCs \\
Dec 2015 & Bundeskartellamt prohibits Booking.com from applying PPCs \\
Nov 2016 & Austrian Parliament approves a law eliminating all PPCs \\
Aug 2017 & Italian Parliament approves Liberalization Law: all PPCs prohibited \\
Nov 2017 & Belgian Government proposes to outlaw all PPCs \\
\hline
\end{tabular}

Following the complaints filed by trade groups representing hotel owners, national competition authorities opened inquiries on Booking.com and other dominant OTAs. In Germany, the Bundeskartellamt prohibited HRS (Hotel Reservation Service) from using Price Parity Clauses and, in December 2015, it reached a similar decision against Booking.com. In April 2015, the French, Italian and Swedish competition authorities accepted Booking.com's commitment to switch from wide to narrow Price Parity Clauses. The commitment came into effect across all EU countries on July 1st, 2015. ${ }^{8}$ These changes affected all the regions in our sample.

In relation to our analysis, in July 2015, the French Parliament passed the Macron Law (Law on Economic Growth and Activity no. 2015-990), according to which all Price Parity Clauses were banned. The provision was promulgated on August 6th, 2015. This event is crucial as it differently impacts the regions we consider. For this reason, it will be the main focus of our empirical analysis. Similar laws were enacted in Austria in November 2016 and in Italy in August 2017: this latter episode (Italy's Liberalization Law no. 124/2017) will also be analyzed in relation to the short-run price effects on the hotels affected by the change.

\footnotetext{
${ }^{8}$ Other countries participating at some stage to the EU investigation were Belgium, the Czech Republic, Germany, Hungary, Ireland, the Netherlands, and the UK.
} 
A first-hand evaluation, mainly focusing on the removal of wide Price Parity Clauses in the EU, was provided by European Competition Network (2017). The analysis was based upon a survey filled out by 16,000 hotels in ten member countries, complemented by data on hotel room prices obtained from major metasearch websites. The report monitored price differentiation and room availability among different sales channels. Its findings point towards: (i) a scarce propensity of hoteliers to charge different prices on alternative sales channels; (ii) a limited awareness of the policy changes that affected the sector; (iii) only minor changes in the commission fees following the major decisions. Our article adds to this evidence by providing a fully fledged identification of the price effects of the complete removal of Price Parity Clauses.

\section{Data}

\subsection{Data collection}

The empirical analysis is based on data retrieved from Booking.com before and after the main events of the 2015-17 period in France and Italy, as described in Table 1. The data cover four tourist regions in the Mediterranean: Corsica (France), Sardinia and Sicily (Italy), and the Balearic Islands (Spain). These regions consist of islands that have fairly similar characteristics and adopt the same currency (the Euro), thereby representing comparable alternatives for potential visitors. Figure 1 shows that the regions are all located in the Western Mediterranean. Corsica and Sardinia are geographically very close to each other, despite administratively belonging to France and Italy, respectively.

Of particular interest for our analysis, the four regions belong to three countries that have been affected by the European inquiries on Booking.com and its successive developments, albeit to different degrees. Indeed, Italy and France were directly involved since the initial investigations. Furthermore, they removed all types of Price Parity Clauses, though at different times: France in August 2015 and Italy in August 2017. Spain, instead, never took action on this issue and, as a result, narrow Price Parity Clauses can still be lawfully enforced there. 


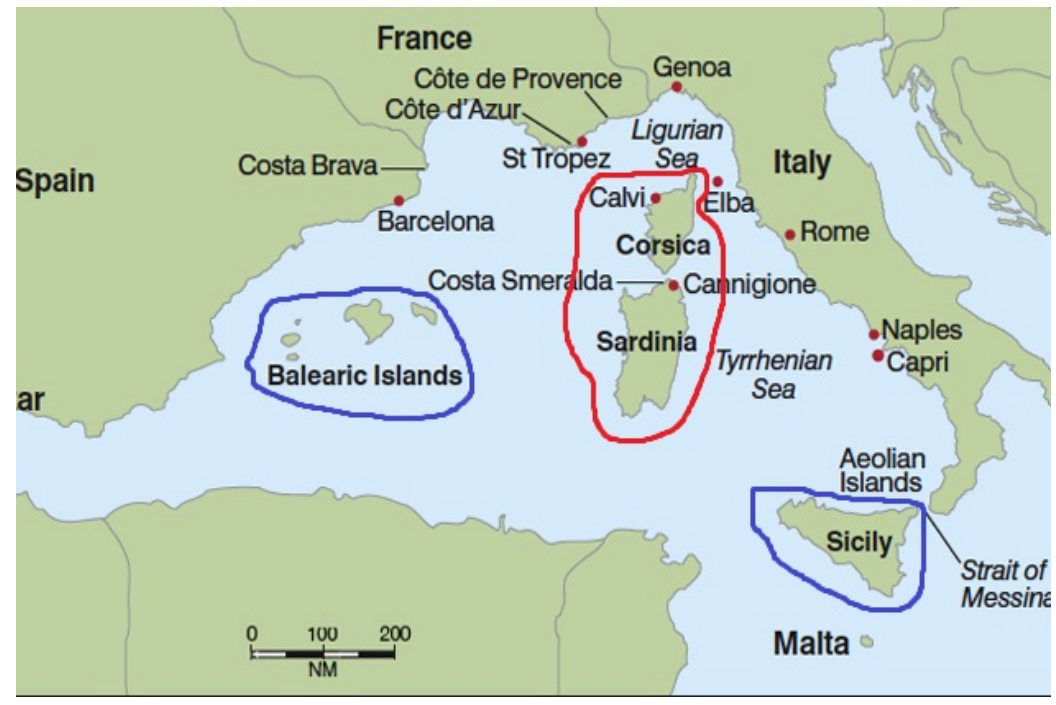

Figure 1: Western Mediterranean Islands

The data were retrieved using a "web crawler", designed to automatically connect to Booking.com. The crawler launched queries to book accommodation in all the lodging establishments in the four regions. It then saved information about the posted prices, collectively with the characteristics of the rooms available at each establishment. The crawler also retrieved data on the characteristics of the lodging establishments (e.g., type of establishment, total number of rooms, star rating, users reviews, etc.) listed on Booking.com during the period of the study. For the purpose of our analysis, we focus only on establishments listed as hotels. ${ }^{9}$

The crawler operated on a daily basis, retrieving information on room prices for the following stay dates: from June 1st to November 30th 2014, from March 17th to November 30th 2015, from August 31st to November 30th 2016, and the entire month of September 2017. Room prices refer to a specific product identified by the combination of hotel, room type and date of stay; prices were tracked during the booking period, i.e., in advance of the stay date, so that we were able to observe whether the pricing of a product changed after a policy measure was implemented.

\footnotetext{
${ }^{9}$ Data on apartments, villas and other lodging establishments tend to be more "noisy". Indeed, many of these are small family-run businesses or private properties rented for the summer period. Their listing and pricing strategies are likely to be affected by a high number of factors (e.g., recurring consumers visiting every year in the same period), the clauses imposed by Booking.com being only one of them. Finally and most importantly, in contrast to aparthotels and B\&Bs, hotels are more likely to have a direct sales channel.
} 
More precisely, for each stay date, the crawler issued queries starting from 70 days prior to and up to one day before the stay. The frequency of the queries was every five to ten days. Within the last fortnight, the query frequency intensified to track more closely the room pricing as the stay date approached. Overall, the information gathered by the crawler amounted to $9,649,100$ price points on 2,574,651 hotel rooms.

\subsection{Sample and descriptive statistics}

The samples used in our D-in-D analyses feature a total of 2064 establishments registered on Booking.com as hotels: 336 in Corsica, 486 in Sardinia, 529 in Sicily and 713 in the Balearic Islands. ${ }^{10}$ Table 2 presents the characteristics of these hotels for each of the regions. Hotels in Corsica, Sardinia and Sicily are relatively more homogeneous than those in the Balearic Islands. In fact, the average size varies between 28 and 38 rooms for the first three regions, as opposed to 100 rooms in the Balearic Islands, whose hotels have more experience using the platform, having started earlier on average (February 2010 versus June-August 2011).

Notice that between 5 and 7 percent of hotels in Corsica, Sardinia and Sicily are affiliated with a chain, as opposed to 33 percent in the Balearic Islands. Importantly for the ensuing analysis, Corsica has 24 chain hotels and Sardinia 23. All islands have a similar average hotel quality, as proxied by both review scores on Booking.com (ranging between 7.9 and 8.3) and star rating (ranging between 2.97 and 3.46).

Table 3 presents an overview of hotel prices in 2015. The focus is on the mean price of a double room, the most common in our sample, for stay dates from April to October, aggregated at monthly level. Figure 2 complements the table presenting information on weekly prices. The table and the figure show that seasonal variability is well captured by the data, and the peak prices are registered in August in all regions. However, the seasonal pattern is less pronounced for Sicily. This may not come as a surprise, as the island has a very rich history, a number of big cities and a milder climate in winter, attracting visitors throughout the year.

\footnotetext{
${ }^{10}$ For the locations in each region of the sample, the data are highly representative of the market as most hotels are listed on Booking.com.
} 
Table 2: Hotel characteristics: Macron Law and Italy Liberalization Law

\begin{tabular}{l|lll|lll}
\hline \hline & Corsica & & \multicolumn{3}{l}{ Sardinia } & \\
\hline & Obs & Mean & StdDev & Obs & Mean & StdDev \\
\hline Number of rooms & 336 & 28.91 & 28.60 & 486 & 38.60 & 52.66 \\
Star rating & 250 & 2.97 & 0.75 & 335 & 3.46 & 0.70 \\
Chain affiliation & 336 & 0.07 & 0.26 & 486 & 0.05 & 0.21 \\
Users' rating & 326 & 7.97 & 0.76 & 468 & 8.30 & 0.72 \\
Number of reviewers & 335 & 272.01 & 219.42 & 479 & 200.04 & 254.87 \\
On Booking.com since & 336 & 01 Aug2011 & 801.09 & 486 & 31 Aug2011 & 867.31 \\
\hline & \multicolumn{7}{|l|}{} & & & & \\
\hline & Sicily & & & Balearic Islands & \\
\hline & Obs & Mean & StdDev & Obs & Mean & StdDev \\
\hline Number of rooms & 529 & 28.09 & 40.81 & 713 & 100.84 & 104.92 \\
Star rating & 339 & 3.30 & 0.80 & 622 & 3.28 & 1.07 \\
Chain affiliation & 529 & 0.06 & 0.24 & 713 & 0.33 & 0.47 \\
Users' rating & 488 & 8.30 & 0.70 & 696 & 8.13 & 0.77 \\
Number of reviewers & 514 & 261.09 & 310.64 & 706 & 269.31 & 320.07 \\
On Booking.com since & 529 & 02 Jun2011 & 980.52 & 713 & 11 Feb2010 & 953.80 \\
\hline \hline
\end{tabular}

Table 3: Mean price in Euros of a double room on Booking.com in 2015

\begin{tabular}{|c|c|c|c|c|c|c|c|}
\hline & April & May & June & July & August & September & October \\
\hline Corsica & 89 & 111 & 128 & 145 & 159 & 126 & 94 \\
\hline Obs & 30,901 & 68,835 & 58,168 & 62,198 & 51,412 & 51,479 & 43,295 \\
\hline Sardinia & 80 & 90 & 113 & 134 & 157 & 111 & 82 \\
\hline Obs & 40,320 & 106,627 & 104,765 & 108,466 & 86,506 & 84,636 & 65,526 \\
\hline Balearic & 102 & 104 & 128 & 153 & 168 & 138 & 105 \\
\hline Obs & 51,382 & 151,821 & 133,337 & 138,745 & 112,205 & 112,311 & 105,927 \\
\hline Sicily & 88 & 93 & 95 & 98 & 111 & 100 & 88 \\
\hline Obs & 57,501 & 118,591 & 115,291 & 128,434 & 95,856 & 91,613 & 88,136 \\
\hline
\end{tabular}




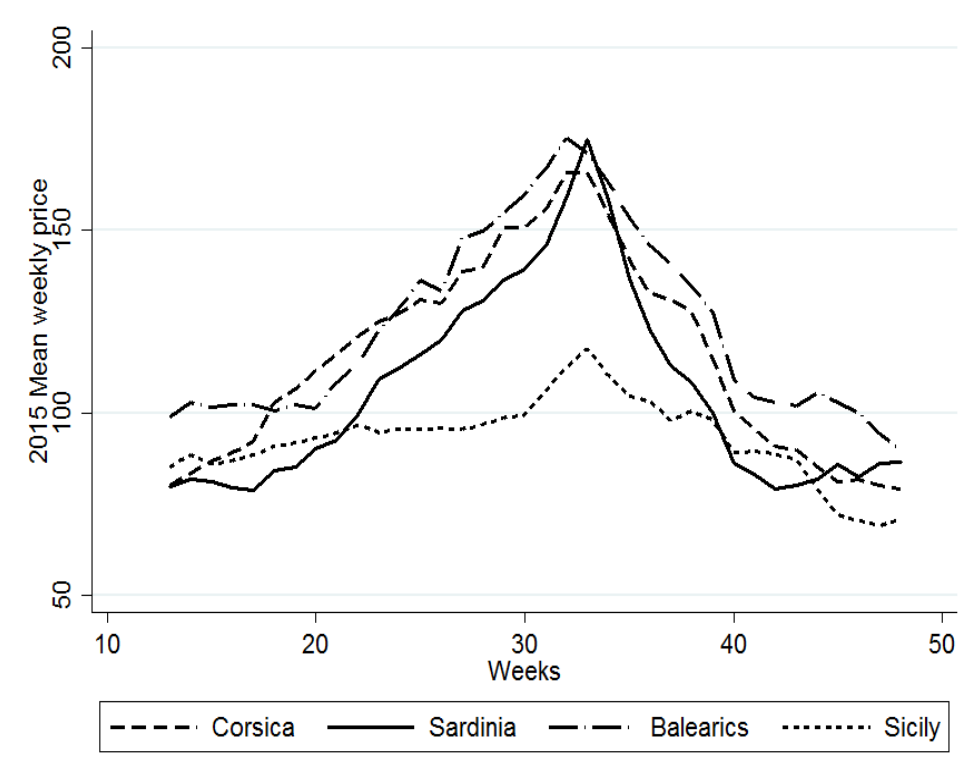

Figure 2: Weekly mean price in Euros of a double room on Booking.com in 2015

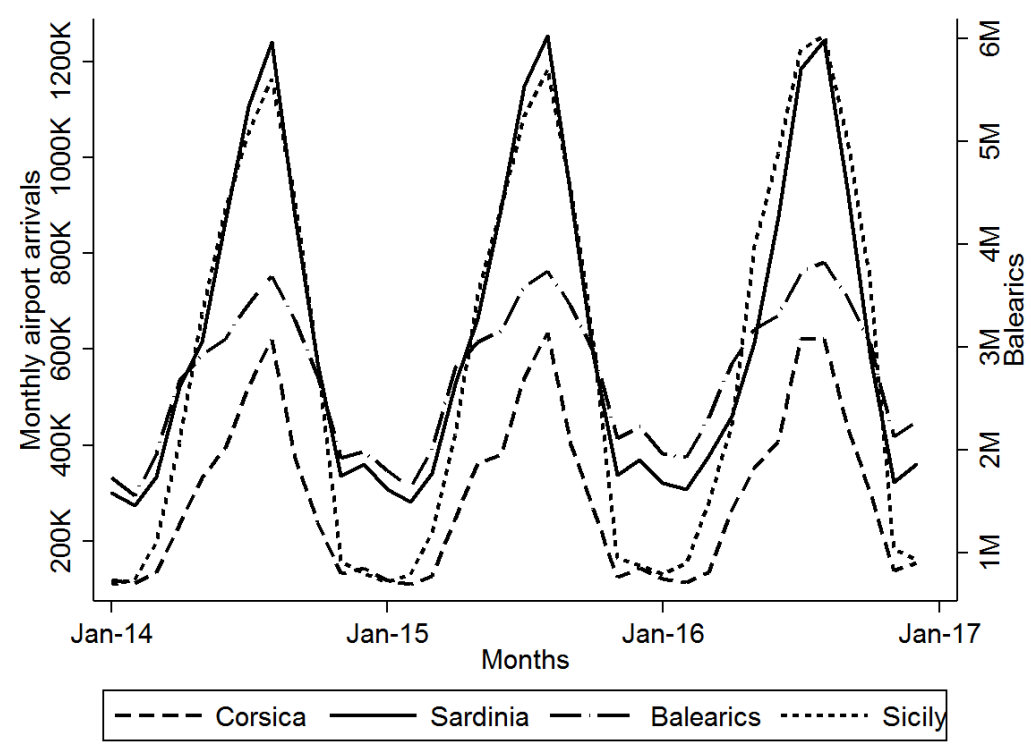

Figure 3: Monthly airport arrivals by region, 2014-16 
Figure 3 displays airport arrivals (number of passengers) in the regions under study, a proxy for tourist flows for the period between January 2014 and January 2017. The figure displays an evident seasonal trend. Compared to the other three regions, a markedly higher number of visitors reach the Balearic Islands by flight.

\section{Empirical strategy}

We aim to evaluate the causal effect of the legislative bans of Price Parity Clauses in France and in Italy, on hotel prices posted on Booking.com. In particular, the events are:

(a) the Macron Law, which came into force in France on August 6th, 2015;

(b) Italy's Liberalization Law, which came into force on August 29th, 2017.

Our data have a panel structure. A panel identifier defines a unique product, $s$, which is the combination of three pieces of information: room type $r$, date of stay $t$, and hotel $i$ of country $j$. The temporal dimension of the panel is denoted by the number of days $d$ ahead of stay. For example, the posted prices of a double room with no breakfast and free cancellation for the 10th of September 2015 at the Hotel Olimpia in Baja Sardinia (Sardinia, Italy) are tracked between 70 days and the last day before the stay, i.e., the 9th of September 2015, a period long enough to include observations before and after the Macron Law implementation.

Given this panel structure, we implement variants of a D-in-D model with fixed effects. The outcome variable, $\ln p_{s d} \times 100$, is the natural logarithm of the price of product $s, d$ days ahead of stay, multiplied by 100 for an easier interpretation of the results. We focus on rooms for stay dates after events (a) and (b) and exploit the variation of room prices along the booking period, before and after these events. In particular, in our 
baseline analysis, we adopt the following specification:

$$
\ln p_{s d} \times 100=\alpha_{s}+\beta_{1} \sum_{j=1}^{R} T R_{j}+\beta_{2} \text { PostLaw }+\beta_{3} T R_{j} \text { PostLaw }+\sum_{j=1}^{R} \eta_{j} d R_{j}+u_{s d}
$$

where $s$ identifies a unique product (room/stay date/hotel) and $d$ the number of days ahead of stay.

The variable $T R$ is a dummy that takes value 1 if the room $s$ is in a "treated" region (e.g., Corsica in event (a), or Sardinia in (b)); Post Law denotes a dummy variable that switches on for room prices posted after the legislation comes into force (e.g., observations collected after August 6th, 2015 in event (a)).

The parameter of interest is $\beta_{3}$, which captures the D-in-D effect of the legislative intervention, our "treatment". For example, for event (a), the coefficient represents the difference between the average percentage price variation before and after the Macron Law, for hotel rooms in Corsica (the "treated group") vis-à-vis hotel rooms in Sardinia (the "control group").

In order to control for possible different trends throughout the booking period, equation (1) also includes a booking time trend for panels in each region $R_{j}, j=1, \ldots, R$. Finally, $\alpha_{s}$ is a product level fixed effect that takes care of potential "local" shocks that may bias the estimates.

Identification of causal effects through model (1) requires a common pre-treatment trend. This drives us to choose Sardinia as the control group for event (a) and Corsica for event (b). ${ }^{11}$ The two regions, in fact, are geographically very close (Figure 1) but institutionally separated, i.e., subject to French and Italian legislation. Moreover, these regions experienced very similar patterns in terms of tourist flows in the period of our study, as confirmed by Figure 3. The hotels on their territory have also relatively similar characteristics (Table 2), as compared, for example, to the Balearic Islands, where hotels of a larger size and affiliated to chains are more common. Finally and most importantly, Figure 2 indicates very similar trends for hotel room prices in aggregate, suggesting common pre-trends in the two regions.

\footnotetext{
${ }^{11}$ We use data on hotels in Sicily and in the Balearic Islands in the robustness check of our analysis.
} 
To recap, the timeline of the events, providing the region-time variation beyond our identification strategy, is also illustrated in Figure 4 .

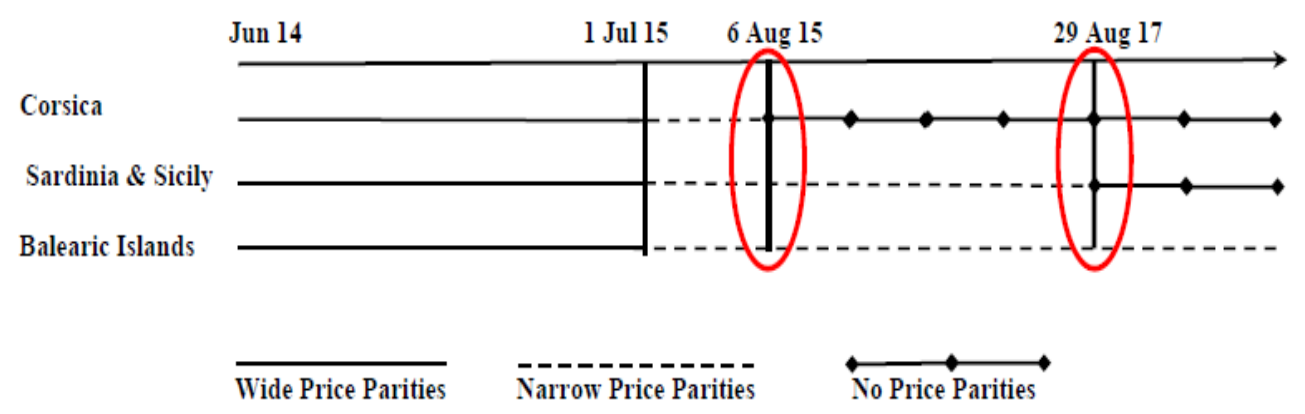

Figure 4: Timeline of the cases by region, 2014-17

The specification in equation (1) focuses on the price effect of the policy change on the average hotel. However, we can identify specific characteristics that may lead to a prompter and more intense response to the elimination of Price Parity Clauses. For instance, chain affiliation provides hotels with informational and reputational advantages (Baum and Ingram, 1998; Hollenbeck, 2017). Similarly, larger size hotels may enjoy economies of scale in information gathering and processing (Abrate and Viglia, 2016). Moreover, a higher review score on Booking.com may signal better managerial practices, including revenue management (Hollenbeck, 2017). Finally, high-star rated hotels are more likely to engage in active pricing (Melis and Piga, 2017).

In order to test for these heterogeneous effects, we interact the $T R$ Post Law terms with hotels grouped by chain affiliation, size, Booking.com's review score, and star rating. The Triple D-in-D model specification used is then:

$$
\begin{array}{r}
\ln p_{s d} \times 100=\alpha_{s}+\beta_{1} \sum_{j=1}^{R} T R_{j}+\beta_{2} \text { PostLaw }+\sum_{k=1}^{G} \beta_{k} \text { Group }_{k} \\
+\sum_{j=1}^{R} \sum_{k=1}^{G} \beta_{j k} T R_{j} \text { PostLaw Group } k+\sum_{j=1}^{R} \eta_{j} d R_{j}+u_{s d}
\end{array}
$$

The parameters of interest are $\beta_{j k}$, which capture the Triple D-in-D effect of the legislation in the treated region on hotels in Group $k, k=1, \ldots, G$. 
Furthermore, given the well-known problems of biased standard errors in D-in-D models (Bertrand, Duflo and Mullainathan, 2004), we follow the suggestion by Angrist and Pischke (2008) to cluster standard errors on a higher level of aggregation, which in our case is the hotel.

Finally, in an effort to keep a relatively balanced panel, in the short-run analysis of the price effects, we focus on three observations before and after the event, when available: the first, the last and the median observation of each panel. As a result of this strategy, for example, about 50 percent of the observations employed to study event (a), i.e., the Macron Law, fall within a window of twenty days before and after this event, and more than 90 percent within a window of thirty days. Additional information on distribution of the width of the windows can be found in Appendix A.

\section{Short-run effects of eliminating Price Parities}

We present the main findings of our investigation on the short-run effects of eliminating all types of Price Parity Clauses on hotel prices listed on Booking.com. Table 4 displays the results of estimating equation (1) for events (a) and (b), i.e., the promulgation of the Macron Law in France on August 6th, 2015 (Column 1), and of Italy's Liberalization Law on August 29th, 2017 (Column 2). The estimates focus on dates of stay between August 22nd and September 30th, 2015, and between September 13th and September 30th, 2017, respectively. These windows of dates characterize our definition of short run.

We find that prices slightly decreased for hotels in the full sample following the Macron Law, whereas they increased after Italy's Liberalization Law (see the coefficients of PostLaw, with a value of -1.143 percent and 3.859 percent, respectively). The D-in-D coefficients of interest (Post$\mathrm{Law}^{*}$ Treated) indicate that hotel prices increased more than in the control group, in both France and Italy (0.457 percent and 1.461 percent, respectively), but these results are not statistically significant.

On the other hand, the coefficients for the number of days before the stay (Days*Corsica and Days*Sardinia) are mostly significant and demonstrate the importance of controlling for different trends throughout the booking period. Overall, the analysis suggests that prices were rather 
steady before and after the legislative interventions.

Table 4: Removing Price Parity Clauses: D-in-D results

\begin{tabular}{|c|c|c|}
\hline Variables & $\begin{array}{c}(1) \\
\text { D-in-D } \\
\text { Macron Law }\end{array}$ & $\begin{array}{c}(2) \\
\text { D-in-D } \\
\text { Italy Liberalization Law }\end{array}$ \\
\hline PostLaw & $\begin{array}{l}-1.143 \\
(0.315)\end{array}$ & $\begin{array}{c}3.859 \\
(1.273)\end{array}$ \\
\hline PostLaw*Treated & $\begin{array}{c}0.457 \\
(0.428)\end{array}$ & $\begin{array}{c}1.461 \\
(2.371)\end{array}$ \\
\hline Days*Corsica & $\begin{array}{c}0.0466 \\
(0.0118)\end{array}$ & $\begin{array}{c}0.0457 \\
(0.0143)\end{array}$ \\
\hline Days*Sardinia & $\begin{array}{c}-0.113 \\
(0.0195)\end{array}$ & $\begin{array}{l}-0.0103 \\
(0.0254)\end{array}$ \\
\hline Constant & $\begin{array}{c}463.7 \\
(0.484)\end{array}$ & $\begin{array}{c}488.5 \\
(1.692)\end{array}$ \\
\hline Observations & 86,629 & 77,198 \\
\hline R-squared & 0.009 & 0.011 \\
\hline Number of panels & 18,806 & 13,891 \\
\hline
\end{tabular}

Notes. Dependent variable: Logarithm of room price $\times 100$.

Column (1). Treated: Corsica; Control: Sardinia; PostLaw: dates after 6 August 2015.

Column (2). Treated: Sardinia; Control: Corsica; PostLaw: dates after 29 August 2017.

Robust standard errors in parentheses, clustered at hotel level.

We can then state:

Finding 1. The elimination of all Price Parity Clauses in France in 2015 and in Italy in 2017 did not bring about significant short-term price changes on Booking.com in both Corsica and Sardinia.

At least in the short run, our results clearly indicate that prices on Booking.com were not significantly affected by the complete removal of Price Parity Clauses. These findings are further illustrated by Figures 5 and 6 , which report the full distribution of the percentage price differentials before and after the two events, by date of stay, aggregated weekly. In each figure, the left panel refers to the treated group and the right panel to the control group. Both for the Macron Law (Figure 5) and for Italy's Liberalization Law (Figure 6), we observe that, although there is a wide span of price differentials (positive and negative), the median of most groups is actually around zero. 


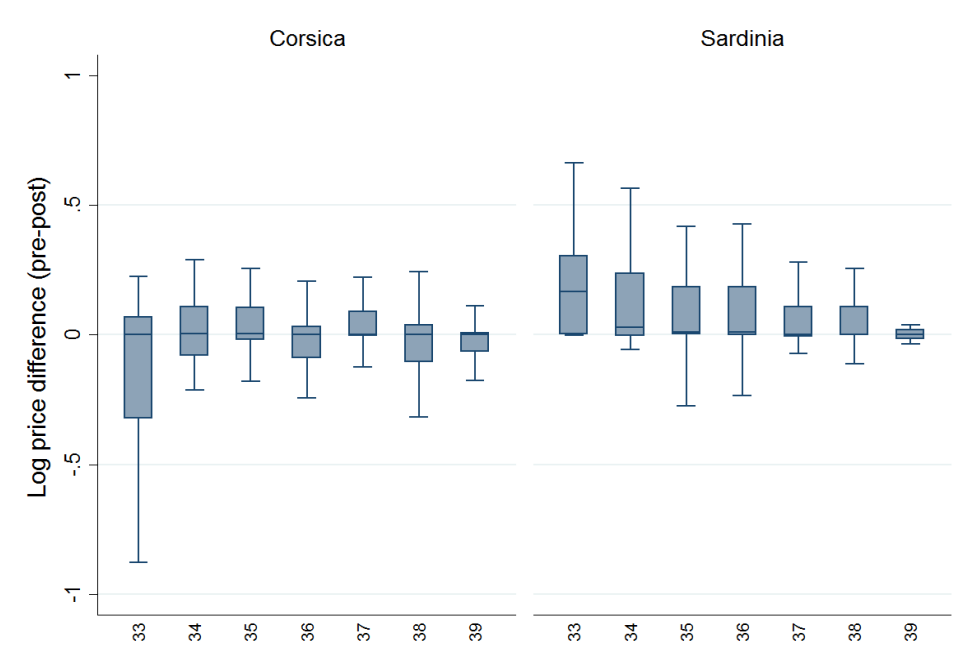

Figure 5: Distribution of short run price changes pre and post Macron Law: Corsica vs Sardinia

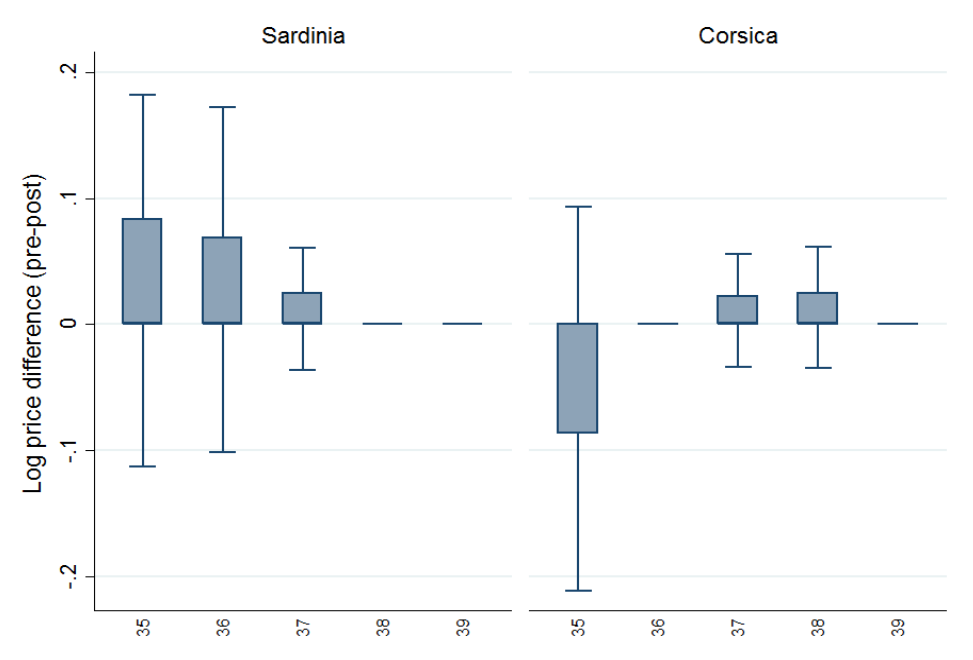

Figure 6: Distribution of short run price changes pre and post Italy's Competition Law: Sardinia vs Corsica 
Our short-run analysis confirms the existence of a certain degree of price sluggishness. ${ }^{12}$ Despite the common wisdom that online prices should promptly adjust to any possible external shock, convincing evidence of the scarce propensity of hotels to change their prices was also obtained by Abrate and Viglia (2016) and Melis and Piga (2017). More generally, similar results on uniform pricing and sticky adjustments are also documented in the context of retail markets by Gorodnichenko, Sheremirov and Talavera (2018), DellaVigna and Gentzkow (2017), and Cavallo (2017), inter alios. The findings are also consistent with the survey evidence in the aforementioned European Competition Network (2017).

We then investigate if specific characteristics have an impact on hotel prices. On the basis of the discussion in Section 4, we define the following four groups. First, we distinguish hotels based on whether or not they are affiliated to a chain. Second, hotels are divided into three groups according to their size: hotels with less than 25 rooms are defined as Small, those with a number of rooms between 25 and 99 are Medium, and hotels featuring more than 99 rooms are Large. Third, hotels are grouped by the quartiles of the Booking.com's review score distribution (Low, Medium-Low, Medium-High and High Rated). Lastly, hotels are categorized by star rating, as reported on Booking.com.

Table 5 shows the Triple D-in-D coefficients for chain affiliation and hotel size in Panel (a), and for Booking.com's review score and star rating in Panel (b), obtained by estimating equation (2). Notice that a significant effect can be found for both events only when considering chain affiliation (PostLaw ${ }^{*}$ Treated ${ }^{*}$ Chain). Indeed, prices of chain hotels declined on average by 5.589 percent in Corsica and by 8.621 percent in Sardinia. Both effects are statistically significant. For hotel size and star rating, a significant price reduction is observed for some categories in France (PostLaw $^{*}$ Treated*MediumsSize, PostLaw*Treated*3Stars, and particularly for PostLaw ${ }^{*}$ Treated ${ }^{*} 4$ Stars). In Sardinia, instead, prices tend to increase, but the coefficients are almost always not significant. Regarding the review score, no significant effects are found for both events.

\footnotetext{
${ }^{12}$ Table 8 in Appendix B provides evidence on active pricing at room level: only between 47 and 51 percent of the rooms in our sample have changed price at least once during the booking period.
} 
Given this, the following can be stated:

Finding 2. The elimination of all Price Parity Clauses in France in 2015 and in Italy in 2017 resulted in a short-run price reduction on Booking.com for hotels affiliated with chains in both Corsica and Sardinia.

The above finding is further illustrated by considering the distribution of the percentage price differentials before and after the two events for chain hotels, reported in Figures 7 and 8. For both the Macron Law (Figure 7) and Italy's Liberalization Law (Figure 8), the values tend to be lower for chain hotels in the treated region than in the control region.

This evidence is important, as it reveals that hotels affiliated with chains are more likely to respond to policy changes than independent hotels, even in the rather limited time covered by our short-run analysis. Such a prompt price adjustment may relate to two aspects that distinguish chain establishments. First, access to better information. Doms, Jarmin and Klimek (2004) point out that in the US economy chain stores invest more in information technology than standalone retailers. According to Baum and Ingram (1998), the chain organizational structure favors information transmission and learning. On top of that, Ater and Rigbi (2015)'s analysis suggests that chains influence the pricing decisions of their franchisees by using informative advertising.

Second, chain hotels possess managerial and organizational capabilities that allow to translate information into pricing strategies. There exists a large body of evidence documenting substantial managerial costs associated to the process of revising prices (Zbaracki et al., 2004; Ellison, Snyder and Zhang, 2018). Nonetheless, Kosová and Lafontaine (2012) underline that hotel and restaurant chains transfer to their franchisees a business format and method that helps them improving the effectiveness of their pricing decisions. Furthermore, Hollenbeck (2017) suggests that better revenue management systems are among the most important advantages of chain affiliation.

Overall, chains seem to be better equipped than independent hotels in acquiring information and overcoming the managerial costs, leading to updated pricing strategies following the implementation of the laws.

We evaluate the robustness of Findings 1 and 2 to a number of alter- 
native specifications. In Appendix C, Table 9, we report the results of estimating equation (1) and (2) under alternative control groups. Panel (a) assesses the robustness of the D-in-D results. We consider hotels in both Sardinia and Sicily as controls in Column (1), and as the treated group in Column (2). In Columns (3) and (4) we also add hotels in the Balearic Islands as a control. The D-in-D coefficients are small and not significant, further supporting Finding 1. Panel (b), instead, focuses on the robustness of the Triple D-in-D effects. Columns (5)-(8) use the same controls as Columns (1)-(4). Both the magnitude and statistical significance of the effects are reduced compared to the benchmark. However, these results confirm more pronounced price decreases for treated chain hotels.

A potential concern of the previous analysis is the sensitivity of the identified effects to the choice of the control group. In order to tackle this issue, we perform a synthetic control group analysis (Abadie and Gardeazabal, 2003; Abadie, Diamond and Hainmueller, 2010). This method relies on a weighted average of control firms (synthetic control) that is as similar as possible to the treated hotels regarding the pre-treatment prices on Booking.com. The benefits of building this synthetic control group is that the characteristics of the treated hotels before the regulatory change can be better approximated by a combination of untreated lodging establishments rather than by an unweighted group of hotels. This methodology has been recently applied in the context of platforms also by Calzada and Gil (2019) and De los Santos and Wildenbeest (2017).

Since the synthetic control analysis requires a strongly balanced panel, we limit our attention to the effect of the Macron Law, for which we have a sufficiently complete dataset in terms of the booking requests. ${ }^{13}$ In Appendix D we provide details about the implementation of the synthetic control analysis together with a graphical representation of the main results. The evidence confirms a rather sluggish short-term price response by hotels in Corsica to the policy change. However, prices tend to diminish in comparison to the synthetic units when considering a slightly longer time horizon, particularly for hotels affiliated with chains.

\footnotetext{
${ }^{13}$ For Italy's Liberalization Law, the pre-treatment period only includes observations taken in May and June, while the post-treatment period was collected in September Whereas these gaps do not affect the D-in-D approach, they make the data less suited for the synthetic control analysis.
} 
Table 5: Heterogeneous effects of removing Price Parity Clauses: Triple D-in-D

\begin{tabular}{|c|c|c|c|c|}
\hline Panel (a) & \begin{tabular}{l}
\multicolumn{1}{c}{$(1)$} \\
Triple D-in-D \\
Macron Law
\end{tabular} & $\begin{array}{c}(2) \\
\text { Triple D-in-D } \\
\text { Italy Liberalization }\end{array}$ & $\begin{array}{c}\text { (3) } \\
\text { Triple D-in-D } \\
\text { Macron Law }\end{array}$ & $\begin{array}{c}(4) \\
\text { Triple D-in-D } \\
\text { Italy Liberalization }\end{array}$ \\
\hline PostLaw $^{*}$ Treated ${ }^{*}$ NoChain & $\begin{array}{c}0.534 \\
(0.436)\end{array}$ & $\begin{array}{c}2.196 \\
(2.455)\end{array}$ & & \\
\hline PostLaw ${ }^{*}$ Treated ${ }^{*}$ Chain & $\begin{array}{c}-5.589 \\
(3.368)\end{array}$ & $\begin{array}{l}-8.621 \\
(3.664)\end{array}$ & & \\
\hline PostLaw*Treated*SmallSize & & & $\begin{array}{c}2.697 \\
(0.710)\end{array}$ & $\begin{array}{l}-1.890 \\
(3.480)\end{array}$ \\
\hline PostLaw ${ }^{*}$ Treated ${ }^{*}$ MediumSize & & & $\begin{array}{c}-4.749 \\
(1.379)\end{array}$ & $\begin{array}{c}3.657 \\
(3.047)\end{array}$ \\
\hline PostLaw*Treated*LargeSize & & & $\begin{array}{l}-4.198 \\
(2.637) \\
\end{array}$ & $\begin{array}{c}3.033 \\
(3.758) \\
\end{array}$ \\
\hline Interactions & Yes & Yes & Yes & Yes \\
\hline Region time trend & Yes & Yes & Yes & Yes \\
\hline Observations & 86,629 & 77,198 & 86,629 & 77,198 \\
\hline R-squared & 0.012 & 0.015 & 0.012 & 0.026 \\
\hline Number of panels & 18,806 & 13,891 & 18,806 & 13,891 \\
\hline Panel (b) & $\begin{array}{l}\text { (5) } \\
\text { Triple D-in-D } \\
\text { Macron Law }\end{array}$ & $\begin{array}{c}\text { (6) } \\
\text { Triple D-in-D } \\
\text { Italy Liberalization }\end{array}$ & $\begin{array}{c}\text { (7) } \\
\text { Triple D-in-D } \\
\text { Macron Law }\end{array}$ & $\begin{array}{c}(8) \\
\text { Triple D-in-D } \\
\text { Italy Liberalization }\end{array}$ \\
\hline PostLaw ${ }^{\star}$ Treated ${ }^{\star}$ LowRated & $\begin{array}{c}0.862 \\
(1.250)\end{array}$ & $\begin{array}{c}2.684 \\
(2.892)\end{array}$ & & \\
\hline PostLaw ${ }^{*}$ Treated ${ }^{*}$ MedLowRated & $\begin{array}{c}-1.842 \\
(1.989)\end{array}$ & $\begin{array}{c}-1.497 \\
(2.997)\end{array}$ & & \\
\hline PostLaw ${ }^{*}$ Treated ${ }^{*}$ MedHighRated & $\begin{array}{c}0.928 \\
(1.816)\end{array}$ & $\begin{array}{c}-3.560 \\
(3.925)\end{array}$ & & \\
\hline PostLaw*Treated ${ }^{*}$ HighRated & $\begin{array}{c}0.469 \\
(1.842)\end{array}$ & $\begin{array}{c}3.283 \\
(4.295)\end{array}$ & & \\
\hline PostLaw ${ }^{*}$ Treated ${ }^{*} 2$ Stars & & & $\begin{array}{l}-4.239 \\
(2.690)\end{array}$ & $\begin{array}{c}-2.102 \\
(2.455)\end{array}$ \\
\hline PostLaw*Treated ${ }^{*} 3$ Stars & & & $\begin{array}{l}-5.387 \\
(2.583)\end{array}$ & $\begin{array}{c}0.309 \\
(2.148)\end{array}$ \\
\hline PostLaw ${ }^{*}$ Treated ${ }^{*} 4$ Stars & & & $\begin{array}{l}-8.106 \\
(2.920)\end{array}$ & $\begin{array}{c}6.179 \\
(3.514)\end{array}$ \\
\hline PostLaw ${ }^{*}$ Treated $^{*} 5$ Stars & & & $\begin{array}{c}0.576 \\
(4.618)\end{array}$ & $\begin{array}{c}3.641 \\
(4.714)\end{array}$ \\
\hline Interactions & Yes & Yes & Yes & Yes \\
\hline Region time trend & Yes & Yes & Yes & Yes \\
\hline Observations & 85,820 & 77,198 & 64,513 & 77,198 \\
\hline R-squared & 0.011 & 0.019 & 0.019 & 0.030 \\
\hline Number of panels & 18,619 & 13,891 & 14,020 & 13,891 \\
\hline
\end{tabular}

Notes. Dependent variable: Logarithm of room price $\times 100$.

Columns (1)-(3)-(5)-(7). Treated: Corsica; Control: Sardinia; PostLaw: nights after 6 August 2015.

Columns (2)-(4)-(6)-(8). Treated: Sardinia; Control: Corsica; PostLaw: nights after 29 August 2017.

Robust standard errors in parentheses, clustered at hotel level. 


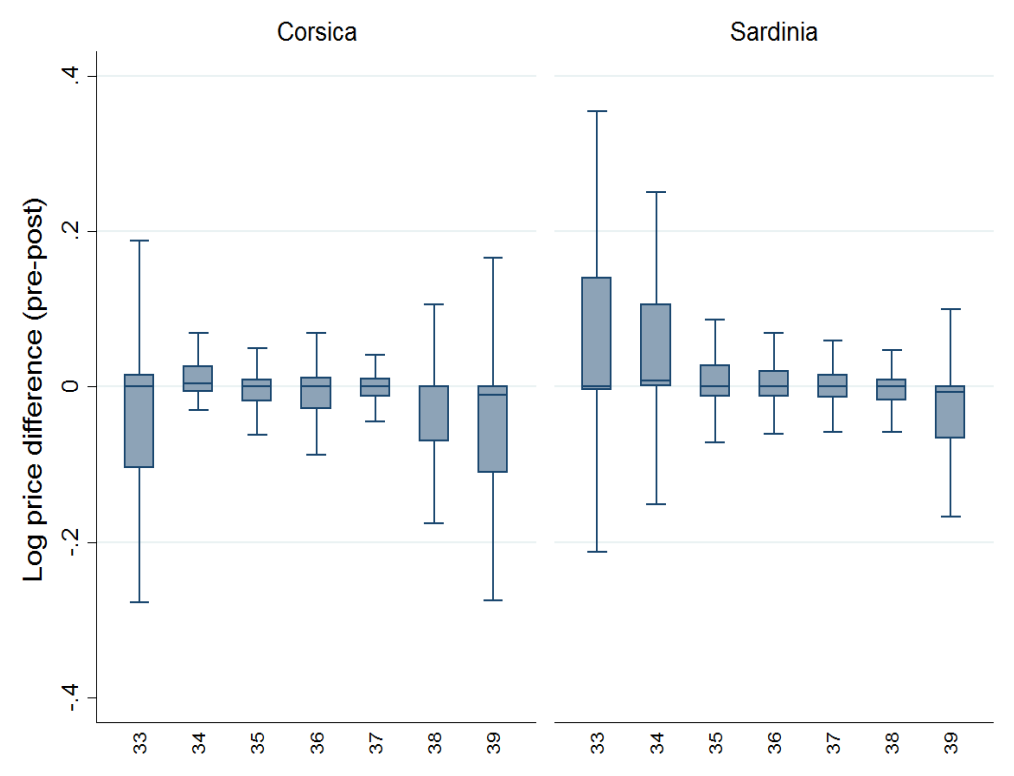

Figure 7: Distribution of short run price changes pre and post Macron Law: Corsica vs Sardinia, chain hotels

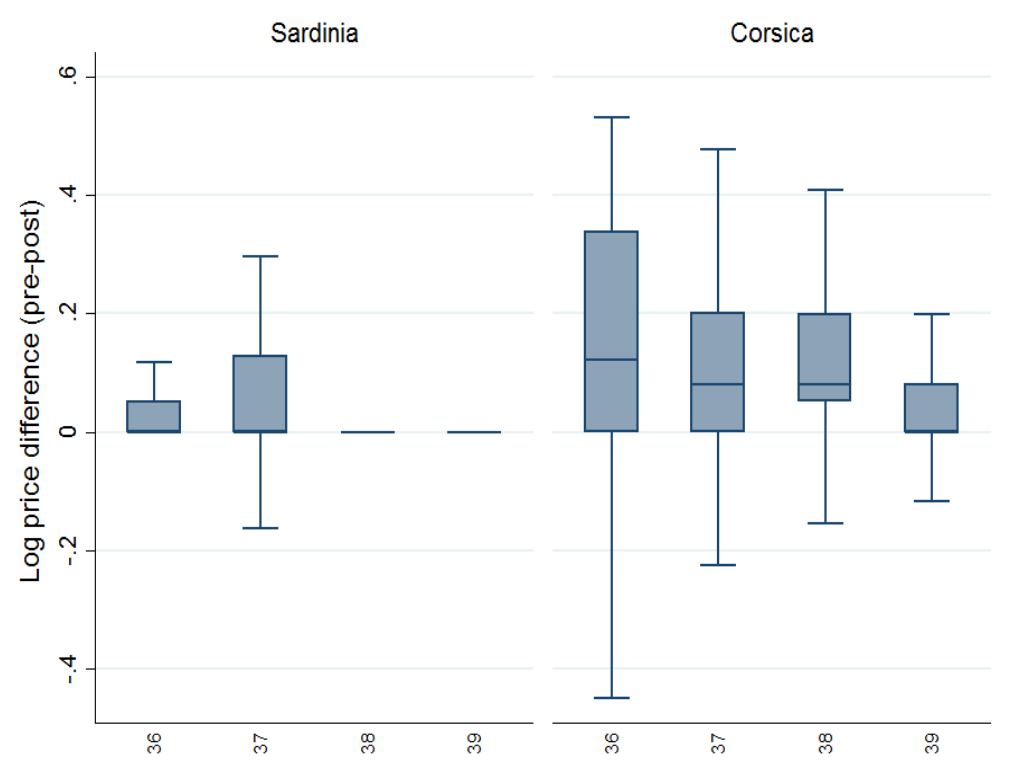

Figure 8: Distribution of short run price changes pre and post Italy's Competition Law: Sardinia vs Corsica, chain hotels 


\section{Medium-run effects of eliminating Price Pari- ties}

The D-in-D analysis carried out in the previous section showed that the complete removal of all Price Parity Clauses did not lead to significant short-run price reductions on Booking.com, with the partial exception of chain hotels. This may hint at a limited response of hotel prices to the policy changes. However, our short-run findings were based on a narrow window of dates in the vicinity of the major legislative events. Hence, we captured only localized and short-run price variations. In this section, we extend our empirical analysis to gauge evidence for the medium-run price effects of the eliminating Price Parity Clauses.

It is conceivable, in fact, that price adjustment can take some time. In the previous section, we discussed the role of information gathering and managerial costs in hindering a more prompt response to the policy changes. In the medium run, hotels should overcome these difficulties, and adapt their pricing strategies to the new institutional environment. Furthermore, the abolition of Price Parity Clauses may strengthen their position when bargaining the agency fees with OTAs.

To study medium-run effects, we only consider the Macron Law and use data taken one year before and after its introduction. ${ }^{14}$ More precisely, we use a window of dates from September 1st to November 30th, allowing to compare exactly the same type of room for the corresponding stay date both before (2014) and after (2016) the event. ${ }^{15}$ In terms of equations (1) and (2), the variable $T R$ is a dummy that takes value 1 if the room $s$ is in the "treated" region of Corsica and PostLaw is active for 2016 observations.

Given the new panel structure described above, we implement again Din-D and Triple D-in-D models with fixed effects, by estimating equations (1) and (2), respectively. We argue that common pre-trend still applies, ensuring the identification of causal effects. The evidence provided in

\footnotetext{
${ }^{14} \mathrm{~A}$ similar analysis of the Italy's Liberalization Law is not possible because the data coverage ends in 2017.

${ }^{15}$ To ensure full comparability, our matching procedure is based on fixing exactly the same day of the week and week of the month (for example, September 6, 2014 and September 3, 2016).
} 
Section 4 is corroborated by Figure 9: also in 2014 aggregate double room prices show a very similar trend for hotels in Corsica and in Sardinia.

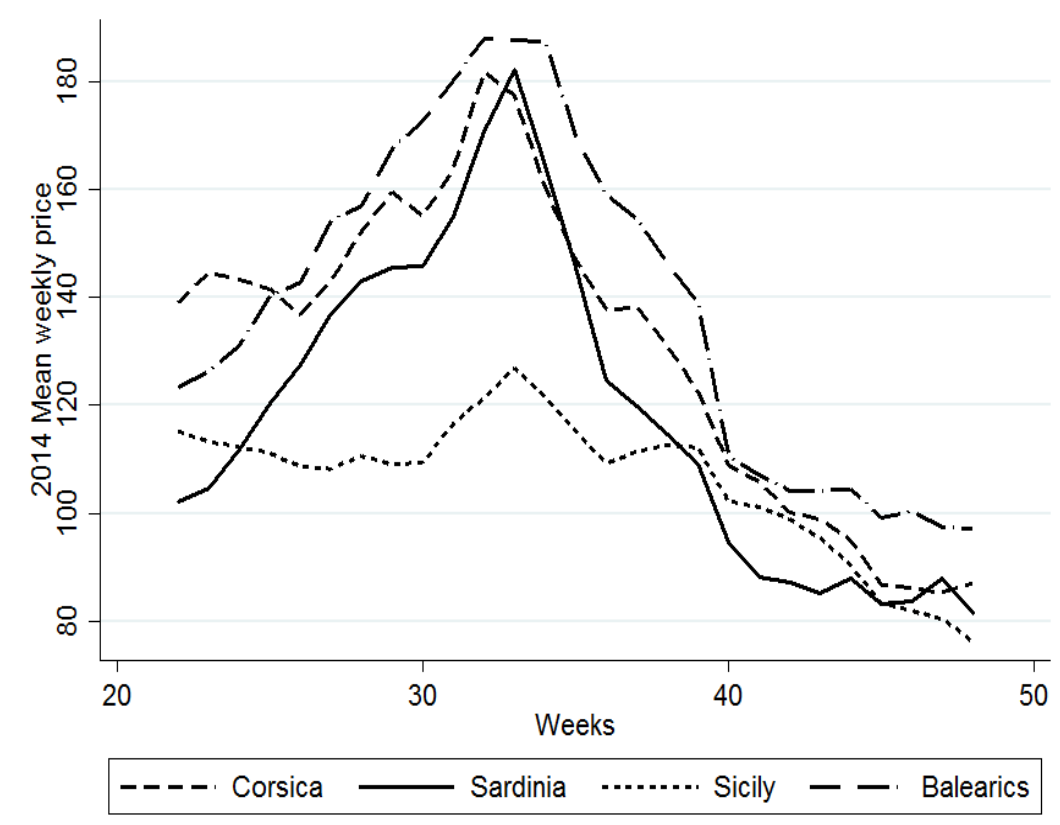

Figure 9: Weekly mean price in Euros of a double room on Booking.com in 2014

Table 6 presents the results of our medium-run analysis. The estimated coefficients of equations (1) and (2) are reported in Columns (1) and (2), respectively. The former considers the D-in-D effect of the Macron Law and it shows that prices decreased on average by 4.094 percent in Corsica relative to Sardinia. Notice that the price change is now statistically significant. The latter shows the Triple D-in-D effect on chain hotels and it confirms that this group is more responsive to the legislative change. Indeed, hotels in Corsica affiliated with chains reduced their price by 12.33 percent with respect to their Sardinian counterparts.

These findings are further illustrated by Figures 10 and 11, which report the full distribution of the percentage price differentials before and after the Macron Law, by date of stay, aggregated weekly. The first figure refers to the full sample, whereas the second one considers hotels affiliated with chains. Both figures confirm that hotels in Corsica decreased their prices more (or increased them less) than hotels in Sardinia.

To sum up, the following can be stated: 
Finding 3. In the medium run, the elimination of all Price Parity Clauses in France in 2015 resulted in an average price reduction of about 4 percent on Booking.com. For hotels affiliated with chains, the price reduction was on average about 12 percent.

Table 6: Medium-run effects of removing price parity clauses: D-in-D and Triple D-in-D evidence

\begin{tabular}{lcccc}
\hline \hline & $(1)$ & $(2)$ & $(3)$ & $(4)$ \\
& $\begin{array}{c}\text { D-in-D } \\
\text { Macron Law }\end{array}$ & $\begin{array}{c}\text { Triple D-in-D } \\
\text { Macron Law }\end{array}$ & $\begin{array}{c}\text { D-in-D } \\
\text { Placebo }\end{array}$ & $\begin{array}{c}\text { Triple D-in-D } \\
\text { Placebo }\end{array}$ \\
\hline PostLaw*Treated & -4.094 & & -2.123 & \\
& $(1.664)$ & & $(1.237)$ & \\
PostLaw*Treated ${ }^{*}$ NoChain & & -3.790 & & -2.057 \\
& & $(1.696)$ & & $(1.260)$ \\
PostLaw*Treated ${ }^{*}$ Chain & & -12.33 & & -2.890 \\
& & $(3.589)$ & & $(5.836)$ \\
\hline Interactions & Yes & Yes & Yes & Yes \\
Region time trend & Yes & Yes & Yes & Yes \\
\hline Observations & 197,169 & 197,169 & 136,369 & 136,369 \\
R-squared & 0.005 & 0.006 & 0.001 & 0.001 \\
Number of panels & 22,840 & 22,840 & 15,735 & 15,735 \\
\hline \hline
\end{tabular}

Notes. Dependent variable: Logarithm of room price $\times 100$.

Columns (1)-(2). Treated: Corsica; Control: Sardinia; PostLaw: nights after 6 August 2015.

Columns (3)-(4). Treated: Corsica; Control: Sardinia. Placebo Test: all observations collected before 1 July 2015. PostLaw: dummy taking value 1 for nights in 2015.

Robust standard errors in parentheses, clustered at hotel level. 


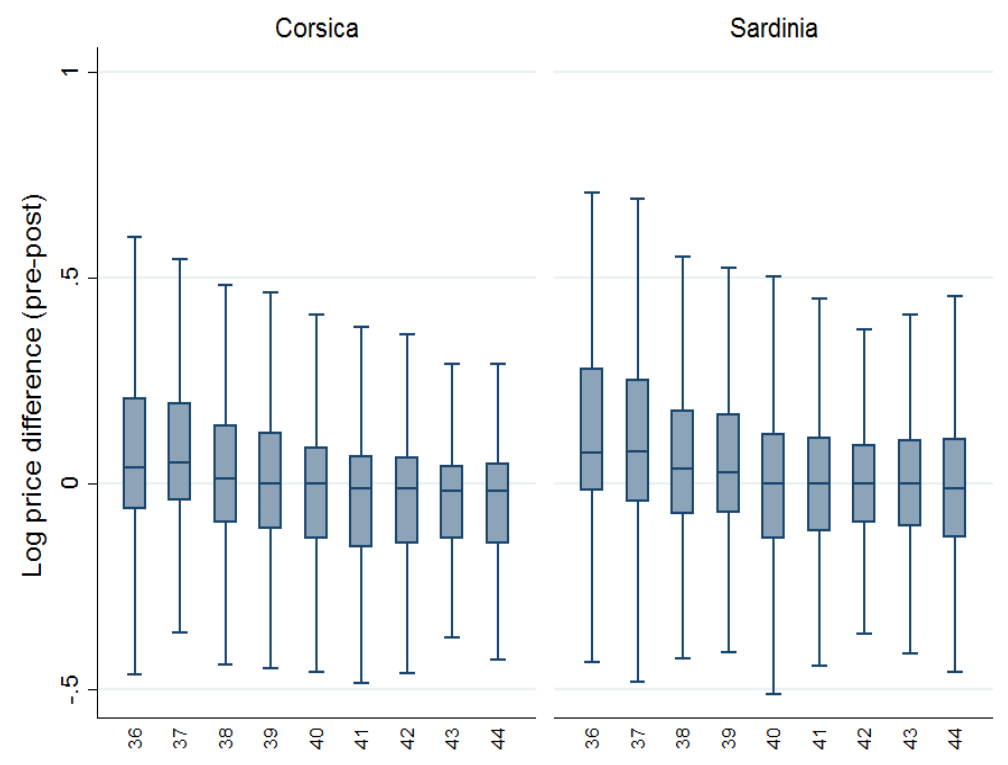

Figure 10: Distribution of the medium-run price changes pre and post Macron Law: Corsica vs Sardinia, 3 and 4 star rated hotels

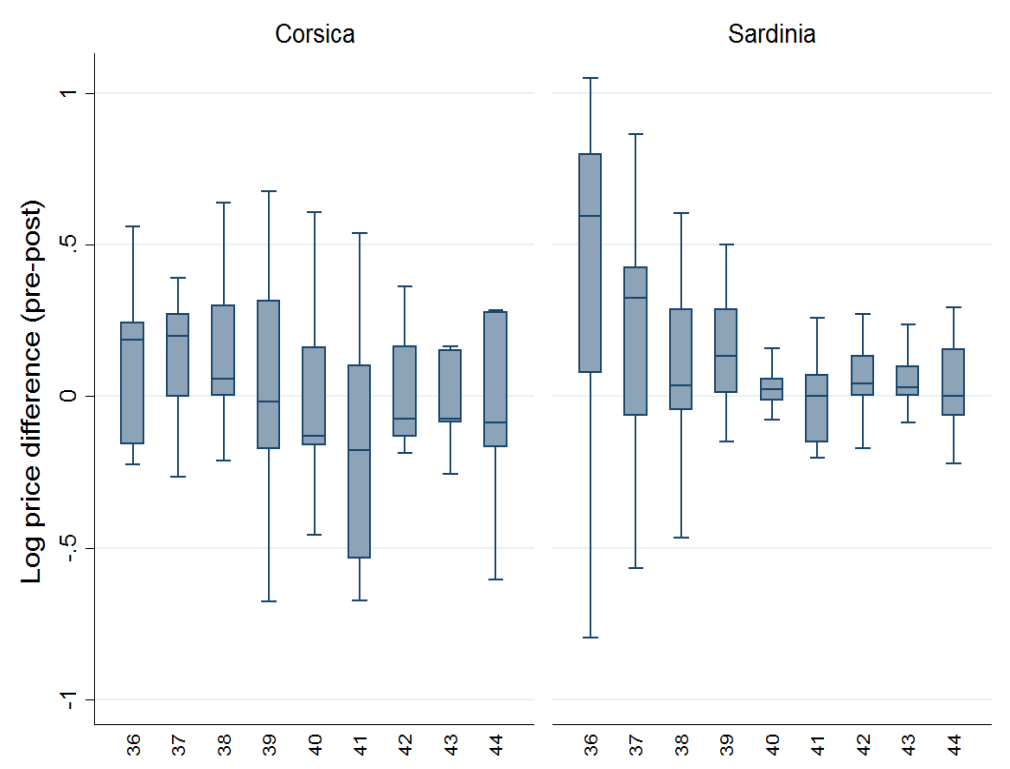

Figure 11: Distribution of the medium-run price changes pre and post Macron Law: Corsica vs Sardinia, 3 and 4 star rated chain hotels 
Our data do not allow to perform a welfare analysis, but we can provide a rough estimate of the implications of these results. In our sample, there are 336 hotels using Booking.com in Corsica, with an average size of 28.91 rooms. We cover 243 days from April 1st to November 30th, during which the 2015 average room price was 127 euros. Hotel occupancy data suggest that $56.3 \%$ of rooms were occupied in Corsica throughout the year. ${ }^{16}$ Since we exclude the low season, we can conjecture an occupancy rate of 60 to $70 \%$ in the period of our study.

On these grounds, we can estimate a potential savings for tourists between 7.36 and 8.59 million euros. The 24 chain hotels in the region are larger in size (48.63) and more expensive (185 euros per room in 2015). The expected savings for their clients ranges between 3.88 and 4.53 million euros. These figures only refer to Corsica and, as affiliation to chains is more common in urban areas, the effects on the French lodging sector are likely much larger. These considerations also hint at potentially large price effects of the full elimination of Price Parity Clauses in economies where chain hotels are a large share, such as the US and the UK.

Our findings seem to confirm that the information and managerial costs, that were likely hindering the short-run response of hotels, are not in operation in the medium run. All hotels, in fact, revised their strategies and, consistently with Johnson (2017) and Wang and Wright (2018), the prices on Booking.com significantly decreased on average. This effect is more pronounced (three times higher) for chain hotels.

Compared to independent hotels, chains also benefit from a stronger bargaining position towards OTAs. In accordance with this interpretation, Hollenbeck (2017) finds that chain affiliation increases reputation, thereby rendering the hotel less reliant on OTAs. This view is backed by the survey results in European Competition Network (2017), according to which the share of sales through OTAs is higher for independent hotels (between 35 and 42 percent) than for chains (between 28 and 35 percent). In other sectors, like groceries supermarkets, chains' buyer power have raised antitrust concerns, and the European Competition Network (2017)

\footnotetext{
${ }^{16}$ Source: Eurostat, Net occupancy rate of bed-places and bedrooms in hotels and similar accommodation (NACE Rev. 2, I, 55.1) by NUTS 2 regions, http://appsso. eurostat.ec. europa.eu/nui/show.do?dataset=tour_occ_anor2\&lang=en.
} 
also confirms that chains usually negotiate contractual terms with OTAs to benefit all the affiliated hotels.

In a related context, Baker and Chevalier (2012) highlight how Most Favored Nation clauses can enhance a manufacturer's bargaining position towards competing retailers. The simulations in De los Santos, O'Brien and Wildenbeest (2018) indicate that platforms in the e-book sector can use price restrictions to shift the bargaining power in their favor. In our setting, the bargaining power of chains materializes in renegotiating the agency fees. Following the elimination of Price Parity Clauses, the expected effects can be appreciated in the medium run and they consist in a significant price drop on Booking.com.

Finding 3 and the results of this section are particularly relevant in terms of their possible policy implications. As such, we perform an additional robustness check by considering a placebo test. Specifically, we run exactly the same analysis but compare stay dates that are all prior to the implementation of the Macron Law, i.e., we compare room prices in June of 2014 with those of June 2015. ${ }^{17}$ Columns (3) and (4) of Table 6 report the Placebo D-in-D and Triple D-in-D effects, respectively. These are all very small and not statistically significant, thus supporting the validity of our medium-run findings.

\section{Concluding remarks}

Online platforms profoundly revolutionized the business model of firms belonging to different sectors. Amid their impressive growth, these platforms have been raising a number of new antitrust challenges and the use of Price Parity Clauses is currently one of the most debated. This article presented the first empirical assessment of the short- and medium-run effect on platform prices of the elimination of these restrictive contractual provisions.

Our analysis was based on data from Booking.com, the most popular OTA in the EU. In particular, we focused on the main antitrust events that affected this platform first in France in 2015 (Macron Law) and then in Italy

\footnotetext{
${ }^{17}$ We only focus on stay dates in June, as on July 1st, 2015 Booking.com's commitment to switch from wide to narrow Price Parity Clauses came into force.
} 
in 2017 (Liberalization Law). Our data on hotels listed on Booking.com before and after the full removal of Price Parity Clauses in these two countries allowed us to implement a D-in-D analysis by comparing hotel prices in Corsica and Sardinia. These two regions are extremely similar and geographically very close to each other.

First, we showed that the complete removal of Price Parity Clauses did not lead to substantial short-run price variations on Booking.com in both regions. The presence of informational and managerial frictions is likely to be responsible for such a sluggish response. In fact, when focusing on chain hotels, that are less affected by the above frictions, our results indicated a significant price reduction of about 5.6 percent in Corsica and 8.6 percent in Sardinia. The results were also confirmed by a synthetic control analysis for the French case, suggesting that more pronounced effects took place towards the end of the short-run period under investigation.

Second, our dataset enabled us to perform a medium-run analysis for the effect of the Macron Law. Interestingly, we found significant price reductions on Booking.com for all types of hotels, with an estimated average drop of about 4 percent. Allowing sufficient time, the aforementioned frictions faded away and all hotels adjusted to the institutional change. Moreover, when taking into account heterogeneous effects, we confirmed that chain hotels were more responsive to the policy change, with an estimated price reduction of 12.3 percent. This pointed to a stronger bargaining position of these establishments towards OTAs.

To sum up, if price variations in response to policy interventions are to be expected, they may not take place in the short run, and not among independent hotels. Significant price reductions are however more likely to occur in the medium run, and especially among chain hotels.

The analysis in the article and the results provided can be especially relevant to policy makers, in a global landscape characterized by heterogeneity. The evidence, in fact, is based on a uniquely detailed database on hotel prices on Booking.com in EU countries which were differently affected by recent interventions against Price Parities Clauses. The EU's action constituted an unprecedented attempt to regulate OTAs. ${ }^{18}$ Moreover, similar

\footnotetext{
${ }^{18}$ In the rest of the world, with exceptions such as Australia, New Zealand and Switzer-
} 
forms of platform Most Favored Nation provisions in industries as diverse as publishing and insurance are receiving increasing attention. Hence, the EU experience may be extremely helpful not only to other countries but also other sectors, in which similar clauses are adopted.

There are two takeaways that can be drawn from our study. First, a short-run price stasis should not surprise regulators, since price reductions are hindered by informational and managerial frictions, and any response to policy changes is more likely to occur in the medium-long run. However, the prompt short-run reaction of chain hotels, that benefit of more effective formal and informal information channels, suggests that any policy intervention should be complemented by an effective information campaign to raise awareness among all stakeholders.

Second, the magnitude of the medium-run price effect on chains hints at the fact that the full removal of restrictive contractual terms may have a different impact, depending on the type of hotels. In particular, the policy intervention seems to have strengthened the position of organized structural units such as chains. In order to also help independent and family run hotels to fully reap the benefits of the regulatory change, policy makers might need to resort to more radical provisions, such as imposing limits to the commission fees.

The analysis carried out in this study is subject to some limitations, mainly relating to the features of the collected data. First, we lack information about quantities. As a consequence, we can provide reduced form evidence on the price effects, but we cannot fully assess the welfare implications of eliminating Price Parity Clauses. Second, our dataset only covers prices posted on Booking.com. Hence, we cannot exclude that possible price reductions occurred on other OTAs, for example Expedia, and /or on hotels' direct sales channels. The complementary results obtained by Hunold et al. (2018) seem to point in this direction, especially for the direct channels. Last but not least, information on the commission rates charged by Booking.com to client hotels is not available.

land, national competition authorities have only recently looked into this issue. 


\section{A Distribution of the dates before and after the events}

In this appendix we report precise information about the width of the windows of dates before and after the two events analyzed in our short-run benchmark specification. Table 7 shows the percentiles of the distribution. More precisely, negative (positive) numbers indicate the distance between the percentile and the last (first) observation retrieved prior to (after) the event. For all events, the table confirms that the vast majority of observations lies within a relatively narrow time span.

Table 7: Distribution of the dates of search by event

\begin{tabular}{ccc}
\hline \hline Percentile & Macron & Italy \\
\hline \hline $5 \%$ & -38 & -33 \\
\hline $10 \%$ & -31 & -28 \\
\hline $25 \%$ & -19 & -18 \\
\hline $50 \%$ & -4 & 5 \\
\hline $75 \%$ & 22 & 11 \\
\hline $90 \%$ & 32 & 20 \\
\hline $95 \%$ & 39 & 25 \\
\hline \hline
\end{tabular}




\section{B Active pricing: panel level evidence}

Table 8 provides evidence on active pricing at room (panel) level. For each event, we report the percentage of dynamic panels by region, defined as rooms for which the price changed by at least 3 Euros throughout the booking period. One can notice that between 47 and 51 percent of the rooms have changed price at least once during the booking period.

Table 8: Dynamic panels

\begin{tabular}{lcc}
\hline \hline & Macron & Italy \\
\hline \hline Corsica & & \\
\% dynamic panels & 49.55 & 47.26 \\
Number of panels & 6,719 & 3,483 \\
\hline Sardinia & & \\
\% dynamic panels & 51.70 & 50.30 \\
Number of panels & 12,087 & 10,408 \\
\hline \hline
\end{tabular}

\section{Robustness of the short run results: alterna- tive control samples}

Table 9 reports the results of estimating equation (1) and (2) under alternative control groups. Panel (a) focuses on the D-in-D effects. Hotels in both Sardinia and Sicily are considered as controls in Column (1), and as the treated group in Column (2). In Columns (3) and (4) we also add hotels in the Balearic Islands as a control. Panel (b) presents the Triple D-in-D effects. Columns (5)-(8) use the same controls as Columns (1)-(4). 
Table 9: Robustness to alternative control groups: D-in-D and Triple D-in-D

\begin{tabular}{|c|c|c|c|c|}
\hline Panel (a) & $\begin{array}{c}(1) \\
\text { D-in-D } \\
\text { Macron } \\
\text { Corsica vs Italy }\end{array}$ & $\begin{array}{c}(2) \\
\text { D-in-D } \\
\text { Italy } \\
\text { Italy vs Corsica }\end{array}$ & $\begin{array}{c}(3) \\
\text { D-in-D } \\
\text { Macron } \\
\text { Corsica vs All }\end{array}$ & $\begin{array}{c}(4) \\
\text { D-in-D } \\
\text { Italy } \\
\text { Sar vs Cor+Bal }\end{array}$ \\
\hline PostTr*Treated & $\begin{array}{c}0.348 \\
(0.411) \\
\end{array}$ & $\begin{array}{l}-1.249 \\
(2.027) \\
\end{array}$ & $\begin{array}{c}-0.302 \\
(0.353) \\
\end{array}$ & $\begin{array}{c}0.256 \\
(2.773) \\
\end{array}$ \\
\hline Interaction & Yes & Yes & Yes & Yes \\
\hline Region time trend & Yes & Yes & Yes & Yes \\
\hline Observations & 150,157 & 147,250 & 222,053 & 192,430 \\
\hline R-squared & 0.006 & 0.034 & 0.005 & 0.020 \\
\hline Number of panels & 32,595 & 26,593 & 48,155 & 35,677 \\
\hline Panel (b) & $\begin{array}{c}\text { (5) } \\
\text { Triple D-in-D } \\
\text { Macron Chain } \\
\text { Corsica vs Italy }\end{array}$ & $\begin{array}{c}(6) \\
\text { Triple D-in-D } \\
\text { Italy Chain } \\
\text { Italy vs Corsica }\end{array}$ & $\begin{array}{c}\text { (7) } \\
\text { Triple D-in-D } \\
\text { Macron Chain } \\
\text { Corsica vs All }\end{array}$ & $\begin{array}{c}(8) \\
\text { Triple D-in-D } \\
\text { Italy Chain } \\
\text { Sar vs Cor+Bal }\end{array}$ \\
\hline PostTr*Treated ${ }^{*}$ NoChain & $\begin{array}{c}0.409 \\
(0.425)\end{array}$ & $\begin{array}{l}-1.146 \\
(2.196)\end{array}$ & $\begin{array}{l}0.0246 \\
(0.380)\end{array}$ & $\begin{array}{c}1.374 \\
(2.910)\end{array}$ \\
\hline PostTr*Treated ${ }^{*}$ Chain & $\begin{array}{c}-2.754 \\
(2.120)\end{array}$ & $\begin{array}{c}-6.997 \\
(3.961)\end{array}$ & $\begin{array}{c}-1.230 \\
(1.766)\end{array}$ & $\begin{array}{c}-3.040 \\
(2.271)\end{array}$ \\
\hline Interaction & Yes & Yes & Yes & Yes \\
\hline Region time trend & Yes & Yes & Yes & Yes \\
\hline Observations & 150,157 & 147,250 & 222,053 & 192,430 \\
\hline R-squared & 0.008 & 0.035 & 0.007 & 0.021 \\
\hline Number of panels & 32,595 & 26,593 & 48,155 & 35,677 \\
\hline
\end{tabular}

Notes. Dependent variable: Logarithm of room price $\times 100$.

(1)-(3)-(5)-(7) Treated: Corsica; Control: Sardinia; PostTr: nights after 6th August 2015.

(2)-(4)-(6)-(8) Treated: Sardinia; Control: Corsica; PostTr: nights after 29th August 2017.

Robust standard errors in parentheses, clustered at hotel level.. 


\section{Synthetic control analysis}

In order to implement the synthetic control analysis for the Macron Law, we collapse our specific search observations data (room-date of stay-days ahead of stay level) into group-week. Given the relatively long period of data coverage, grouping observations by week allows for a clear data visualization. We define our groups by region (Corsica, Sardinia, Sicily, and Balearic Islands) and hotel size (Small, Medium, and Large). This categorization enables us to create a synthetic control group for the average treated hotel and nine potential controls. The program creates optimal weights using the logarithm of Booking.com's prices for the pre-treatment period and a number of other co-variates (e.g., the days ahead of stay, the chain affiliation dummy, the hotels' capacity, the users' rating and the number of reviewers on the platform, the hotels' experience using Booking.com and the town level availability of hotels).

Figure 12 show the logarithm of prices (multiplied by 100) of all types hotels listed on Booking.com for the treated units and their synthetic counterparts before and after the Macron Law. Figure 13 considers only hotels affiliated with chains. In both cases, the synthetic control closely tracks the average treated hotels, prior to the legislative intervention. After the event, the average treated hotels keep following the respective synthetic control units, slightly diverging in the last periods covered by our samples. Prices tend to decrease in the treated unit, and this is particularly evident for hotels affiliated with chains. 


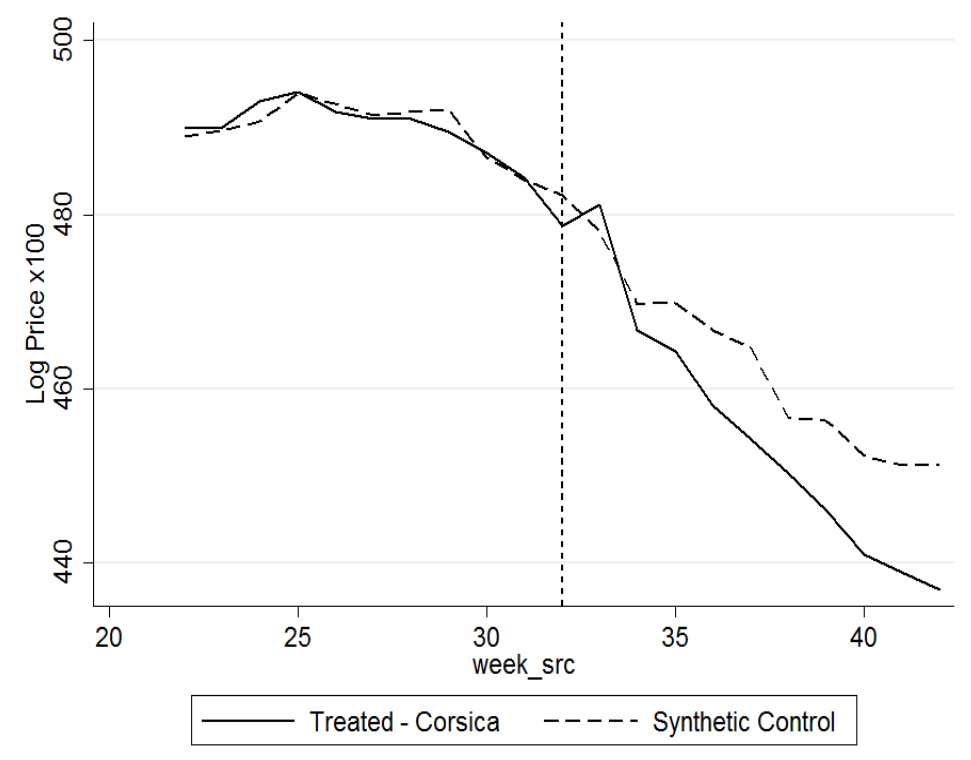

Figure 12: Synthetic controls and hotel prices pre and post the Macron Law: weekly data

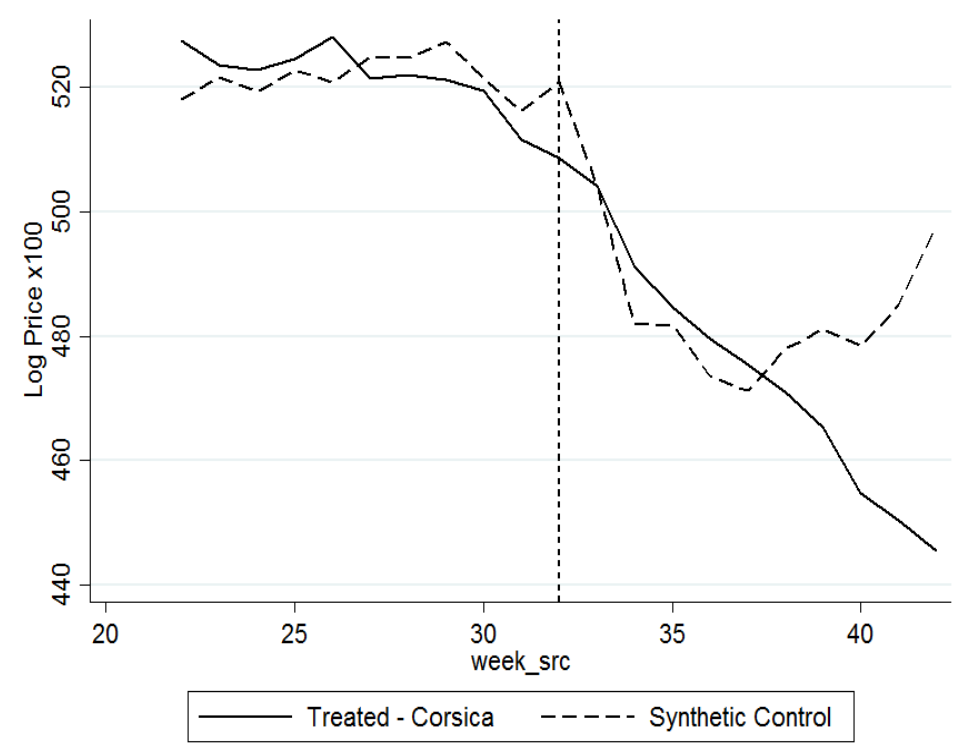

Figure 13: Synthetic controls and hotel prices pre and post the Macron Law: weekly data, chain hotels 


\section{References}

Abadie, Alberto, Alexis Diamond, and Jens Hainmueller. 2010. "Synthetic control methods for comparative case studies: Estimating the effect of California's tobacco control program." Journal of the American Statistical Association, 105(490): 493-505.

Abadie, Alberto, and Javier Gardeazabal. 2003. "The economic costs of conflict: A case study of the Basque Country." American Economic Review, 93(1): 113-132.

Abrate, Graziano, and Giampaolo Viglia. 2016. "Strategic and tactical price decisions in hotel revenue management." Tourism Management, 55: 123-132.

Angrist, Joshua D, and Jörn-Steffen Pischke. 2008. Mostly harmless econometrics: An empiricist's companion. Princeton university press.

Ater, Itai, and Oren Rigbi. 2015. "Price control and advertising in franchising chains." Strategic Management Journal, 36(1): 148-158.

Ater, Itai, and Oren Rigbi. 2018. "The effects of mandatory disclosure of supermarket prices." Mimeo.

Baker, Jonathan, and Fiona Scott Morton. 2018. "Antitrust Enforcement Against Platform MFNs." Yale Law Journal, 33(1): 2176-2202.

Baker, Jonathan B, and Judith A Chevalier. 2012. "The competitive consequences of most-favored-nation provisions." Antitrust, 27: 20.

Baum, Joel AC, and Paul Ingram. 1998. "Survival-enhancing learning in the Manhattan hotel industry, 1898-1980." Management Science, 44(7): 996-1016.

Bertrand, Marianne, Esther Duflo, and Sendhil Mullainathan. 2004. "How much should we trust differences-in-differences estimates?" Quarterly Journal of Economics, 119(1): 249-275.

Boik, Andre, and Kenneth S Corts. 2016. "The effects of platform mostfavored-nation clauses on competition and entry." Journal of Law and Economics, 59(1): 105-134. 
Calzada, Joan, and Ricard Gil. 2019. "What Do News Aggregators Do? Evidence from Google News in Spain and Germany." Marketing Science, forthcoming.

Cavallo, Alberto. 2017. "Are online and offline prices similar? evidence from large multi-channel retailers." American Economic Review, 107(1): 283-303.

Cazaubiel, Arthur, Morgane Cure, Bjørn Olav Johansen, and Thibaud Vergé. 2018. "Substitution between Online Distribution Channels: Evidence from the Oslo Hotel Market." University of Bergen, Working Papers in Economics 08/18.

Chen, Jihui, and Qihong Liu. 2011. "The Effect Of Most-Favored Customer Clauses On Prices." Journal of Industrial Economics, 59(3): 343-371.

Crocker, Keith J, and Thomas P Lyon. 1994. "What do "facilitating practices" facilitate? An empirical investigation of most-favored-nation clauses in natural gas contracts." Journal of Law and Economics, 37(2): 297322.

DellaVigna, Stefano, and Matthew Gentzkow. 2017. “Uniform pricing in US retail chains." NBER Working Paper 23996.

De los Santos, Babur, and Matthijs R Wildenbeest. 2017. "E-book pricing and vertical restraints." Quantitative Marketing and Economics, 15(2): 85-122.

De los Santos, Babur, Daniel P O'Brien, and Matthijs R Wildenbeest. 2018. "Agency Pricing and Bargaining: Evidence from the E-Book Market." NET Institute Working Paper, 18-14.

Doms, Mark E, Ron S Jarmin, and Shawn D Klimek. 2004. "Information technology investment and firm performance in US retail trade." Economics of Innovation and new Technology, 13(7): 595-613.

Edelman, Benjamin, and Julian Wright. 2015. "Price coherence and excessive intermediation." Quarterly Journal of Economics, 130(3): 12831328. 
Ellison, Sara Fisher, Christopher Snyder, and Hongkai Zhang. 2018. "Costs of managerial attention and activity as a source of sticky prices: Structural estimates from an online market." NBER Working Paper 24680.

European Competition Network. 2017. "Report on the monitoring exercise carried out in the online hotel booking sector by EU competition authorities in 2016." European Commission.

Fletcher, Amelia, and Morten Hviid. 2017. "Broad Retail Price MFN Clauses: Are they RPM “at its Worst"?" Antitrust Law Journal, 81(1): 6198.

Gorodnichenko, Yuriy, and Oleksandr Talavera. 2017. "Price setting in online markets: Basic facts, international comparisons, and cross-border integration." American Economic Review, 107(1): 249-82.

Gorodnichenko, Yuriy, Viacheslav Sheremirov, and Oleksandr Talavera. 2018. "Price setting in online markets: Does IT click?" Journal of the European Economic Association, 16(6): 1764-1811.

Hollenbeck, Brett. 2017. "The economic advantages of chain organization." The RAND Journal of Economics, 48(4): 1103-1135.

Hunold, Matthias, Reinhold Kesler, Ulrich Laitenberger, and Frank Schlütter. 2018. "Evaluation of best price clauses in hotel booking." International Journal of Industrial Organization, 61: 542-571.

Johansen, Bjørn Olav, and Thibaud Vergé. 2017. "Platform price parity clauses with direct sales." University of Bergen, Working Papers in Economics 01/17.

Johnson, Justin P. 2017. "The agency model and MFN clauses." Review of Economic Studies, 84(3): 1151-1185.

Kosová, Renáta, and Francine Lafontaine. 2012. "Much ado about chains: A research agenda." International Journal of Industrial Organization, 30(3): 303-308. 
Melis, Giuseppe, and Claudio A Piga. 2017. "Are all online hotel prices created dynamic? An empirical assessment." International Journal of Hospitality Management, 67: 163-173.

Ronayne, David, and Greg Taylor. 2019. "Competing Sales Channels." University of Oxford, Working Paper 843.

Scott Morton, Fiona. 1997. "The Strategic Response by Pharmaceutical Firms to the Medicaid Most-Favored-Customer Rules." RAND Journal of Economics, 28(2): 269-290.

Wals, Francisca, and Maarten Pieter Schinkel. 2018. "Platform Monopolization by Narrow-PPC-BPG Combination: Booking et al." International Journal of Industrial Organization, 61: 572-589.

Wang, Chengsi, and Julian Wright. 2018. "Search platforms: Showrooming and price parity clauses." Working Paper.

Zbaracki, Mark J, Mark Ritson, Daniel Levy, Shantanu Dutta, and Mark Bergen. 2004. "Managerial and customer costs of price adjustment: direct evidence from industrial markets." Review of Economics and Statistics, 86(2): 514-533. 